\title{
TERRITORIALITY, MOTIVATIONAL CLIMATE, AND IDEA IMPLEMENTATION: WE REAP WHAT WE SOW
}

\author{
WEIWEI HUO AND HUANG YI \\ Shanghai University \\ CHENGHAO MEN AND JINLIAN LUO \\ Tongji University \\ XIANMIAO LI \\ Anhui University of Science and Technology \\ KWOK LEUNG TAM \\ Sydney University of Technology
}

\begin{abstract}
Drawing on the integrated perspectives of territoriality and motivational climate, we explored the relationship between employees' territoriality and idea implementation. We tested our model with 46 research and development teams in China, comprising 359 employees and supervisors, who completed measures of territoriality, social alienation, motivational climate (specifically, performance climate and mastery climate), and idea implementation. The results showed that social alienation mediated the relationship between territoriality and idea implementation, and that mastery climate and performance climate moderated the positive relationship between territoriality and social alienation. Our findings not only provide insight into the relationship between territoriality and idea implementation, but also clarify the effect of motivational climate on this relationship. Implications for practice and future research are discussed.
\end{abstract}

Keywords: territoriality, idea implementation, social alienation, work climate, motivational climate, mastery climate, performance climate, innovation.

Weiwei Huo and Huang Yi, SHU-UTS SILC Business School, Shanghai University; Chenghao Men and Jinlian Luo, School of Economics and Management, Tongji University; Xianmiao Li, Anhui University of Science and Technology; Kwok Leung Tam, INSEARCH, Sydney University of Technology.

This paper was supported by the Humanities and Social Science Project of the Ministry of Education in China (13YJC630057) and the National Natural Science Foundation of China (71302048, 71472137).

Correspondence concerning this article should be addressed to Chenghao Men, School of Economics and Management, Tongji University, Tongji Building A, Siping Road 1500, Shanghai 200092, People's Republic of China. Email: sdytmch@163.com 
Innovation encompasses idea implementation, which involves the transfer of novel and useful ideas into a product, service, or production process, and idea generation, which emphasizes the creation of new and useful ideas (Anderson, Potočnik, \& Zhou, 2014). Kambil (2002) showed that just $12.5 \%$ of managers believe that idea implementation is more difficult than idea generation although Baer (2012) reported that, compared to idea generation, idea implementation necessitates more supportive resources and effective collaboration. However, previous researchers have mainly focused on the factors influencing idea implementation from the perspective of social networks and leaders' support (Škerlavaj, Černe, \& Dysvik, 2014); thus, little attention has been given to systematically exploring the transfer between idea generation and idea implementation from the perspective of territoriality.

Therefore, we examined if and how territoriality is associated with idea implementation. Territoriality refers to an individual's behavioral expression of his or her feelings of ownership toward a physical or social object (Peng, 2013). Drawing on social exchange theory (Blau, 1986) and the norm of reciprocity (Gouldner, 1960), we proposed that social alienation would mediate the relationship between territoriality and idea implementation. More specifically, when employees exhibit territoriality in protecting their creative ideas, they are viewed as selfish and are likely to be socially alienated (Zhang, Chan, Zhong, \& Yu, 2016). Accordingly, their colleagues may provide negative feedback, such as displaying noncooperation and resistance or not supplying relevant resources (Ntoumanis \& Biddle, 1999), which, in turn, inhibits idea implementation. Therefore, we explored the mediating role of social alienation in the relationship between territoriality and idea implementation, with the aim of determining why territoriality inhibits the effective implementation of good ideas.

If territoriality inhibits idea implementation, managers of organizations should identify how to weaken this effect. According to Poortvliet and Giebels (2012), a motivational climate, which refers to employees' perception of the extant criteria of success and failure in the workplace (Nerstad, Roberts, \& Richardsen, 2013), may influence individuals' behaviors in social exchange situations 
(Poortvliet \& Giebels, 2012). Further, motivational climate includes performance climate and mastery climate components. Mastery climate refers to individual effort and cooperation, and is beneficial for team members' positive adaption, such as a high level of work engagement and positive exchange relationships (Nerstad et al., 2013); these, in turn, prompt idea implementation. In contrast, performance climate, in which the social comparison and competition within a team is emphasized, may lead to a negative exchange relationship (Nerstad et al., 2013), thereby inhibiting idea implementation. Moreover, prior idea implementation research has been mainly focused on the individual level, and it is difficult to clarify the interaction effects from a single level (Richter, Hirst, van Knippenberg, \& Baer, 2012).

Thus, we examined the boundary condition of the territorialityidea implementation link by examining the moderating role of motivational climate on this relationship. In general, we aimed to use a territoriality perspective to resolve the dilemma of how to translate idea generation into idea implementation by answering two research questions: (1) What is the relationship between territoriality and idea implementation? (2) How does territoriality influence idea implementation?

\section{Literature Review and Hypotheses}

\section{Territoriality, Social Alienation, and Idea Implementation}

Brown, Lawrence, and Robinson (2005) argued that paying greater attention to territoriality may cause individual team members to ignore communication with other colleagues and lack resource exchange channels. On the basis of social exchange theory and the norm of reciprocity, in such a teamwork context these employees may be socially alienated (Zhang et al., 2016). Ownership of key resources is the main motivation for individual territorial behaviors (Brown et al., 2005). Compared to office space, equipment, and other tangible objects, the ownership of intangible resources, such as knowledge and ideas, is difficult for colleagues to identify; thus, employees are more inclined to protect their ownership of intangible resources (Brown et al., 2005). At the same time, the uniqueness of employees' creative ideas is a way to maintain core competitiveness within an organization, whereas the 
loss of control of ideas may decrease employees' special status in the organization. Peng (2013) also showed that creative ideas are important territorial resources. Thus, we defined creative territoriality as an individual or a group taking actions to build, declare, sustain, or recast the control of their territoriality over creative ideas.

Avey, Avolio, Crossley, and Luthans (2009) illustrated that territoriality can inhibit employees' social exchange behaviors and lead to protection of their own belongings. We argue that employees with strong territoriality will pay more attention to building and protecting their territorial resources, overlooking interaction and reciprocity with other colleagues, which, in turn, will reduce the possibility of acquiring supportive resources, in social exchange situations.

Social alienation refers to a state of psychological disengagement that generalizes across one's self-image and social relationships both inside and outside of work contexts (Banai \& Reisel, 2007; Chiaburu, Diaz, \& De Vos, 2013). Baer (2012) argued that idea implementation is a social exchange process, and interpersonal networks are crucial for obtaining the necessary resources for idea implementation. Oldham and Da Silva (2015) also argued that digital technology can help individual team members to connect with others and access supportive resources. Thus, communication and cooperation are two important factors in facilitating idea implementation. However, per the norm of reciprocity, individual employees with high levels of territoriality will attract colleagues' negative feedback, leading to social alienation. Further, per social resource theory (Hobfoll, Freedy, Lane, \& Geller, 1990), when individual employees are alienated from their colleagues due to territoriality, it may be difficult for them to obtain necessary resources, thus inhibiting idea implementation. Therefore, we proposed the following hypothesis:

Hypothesis 1: Social alienation will mediate the relationship between territoriality and idea implementation.

\section{The Moderating Roles of Mastery Climate and Performance Climate}

A motivational climate, as derived from achievement goals theory (Ames, 1992), is emphasized through the policies, practices, and procedures of the work environment (Nerstad et al., 2013). We 
believe that this type of climate will be useful for identification of the kind of behaviors that will be recognized and rewarded in an organization (Schulte, Ostroff, Shmulyian, \& Kinicki, 2009).

The mastery climate component of a motivational climate can create perceptions of a shared fate and promote supportive behavior among employees. In such circumstances, employees who consider their own interests will also take into consideration the interests of other colleagues (Swift, Balkin, \& Matusik, 2010), such that information sharing and cooperation will be emphasized, and the norm of reciprocity will be weakened (Poortvliet \& Giebels, 2012). Thus, a high mastery climate should mean that the norm of team cooperation relieves the social alienation of employees who display territorial behaviors.

In contrast, in the performance climate component of a motivational climate, normative criteria for success are emphasized (Roberts, 2012). That is, organizations with a high level of performance climate emphasize internal competition and social comparison. More specifically, exclusive ideas can gain one a competitive advantage and simultaneously weaken other colleagues' performance, thus increasing the possibility of one's success in the organization. Drawing on social information processing theory (Salancik \& Pfeffer, 1978), employees compare offered inducements with expected contributions, and believe that internal competition is encouraged in an organization with a high performance climate. Consequently, when employees perceive other colleagues' territorial behaviors, the norm of reciprocity indicates that they may provide negative feedback and take actions that will reduce cooperation and increase social alienation (Poortvliet \& Giebels, 2012). Thus, we proposed the following hypotheses:

Hypothesis 2a: Mastery climate will moderate the relationship between territoriality and social alienation, such that a higher level of mastery climate will weaken this relationship.

Hypothesis 2b: Performance climate will moderate the relationship between territoriality and social alienation, such that a higher level of performance climate will strengthen this relationship.

Assuming that mastery climate and performance climate will moderate the relationship between territoriality and social 
alienation, and considering that social alienation is negatively related to idea implementation, it is logical to propose that mastery climate and performance climate will also moderate the strength of the mediating mechanism of social alienation in the relationship between territoriality and idea implementation, forming a mediated moderation model (Edwards \& Lambert, 2007). Thus, we formed the following hypotheses:

Hypothesis 3a: A lower level of mastery climate will strengthen the mediating role of social alienation in the relationship between territoriality and idea implementation.

Hypothesis 3b: A higher level of performance climate will strengthen the mediating role of social alienation in the relationship between territoriality and idea implementation.

\section{Method}

\section{Participants and Procedure}

We collected data from 46 research and development teams located in Beijing, Shanghai, and Hangzhou, China. Before conducting the study, we introduced the research purpose and obtained informed consent from the participants. To reduce the likelihood of common method bias (Podsakoff, MacKenzie, Lee, \& Podsakoff, 2003), employees reported territoriality and motivational climate at Time 1 , then at Time 2 (6 months later) employees reported social alienation and their supervisors were asked to assess the employees' idea implementation. Because our study involved two levels of variables, teams with response rates of less than $80 \%$ were deleted from the study, and the final sample used in the analyses comprised 359 employees and 46 supervisors. Team size ranged from 5 to 10 members and demographic data are shown in Table 1.

\section{Measures}

To ensure the reliability and validity of the scales, we followed Brislin's (1980) translation-back-translation procedure and revised the phrasing of the items according to the preliminary investigation.

Territoriality. We measured territoriality using Avey et al.'s (2009) four-item scale. A sample item is "I feel I need to protect my ideas from being used by others in my organization." Avey et al. reported a Cronbach's alpha coefficient of .86 . 
Social alienation. We assessed social alienation using Banai and Reisel's (2007) six-item scale. A sample item is "Too many people in our organization are just out for themselves and do not really care for anyone else." Banai and Reisel reported a Cronbach's alpha coefficient of .79.

Motivational climate. We measured motivational climate using Nerstad et al.'s (2013) 14-item scale, which includes the dimensions of performance climate (eight items) and mastery climate (six items). A sample item for performance climate is "In my work group, only those employees who achieve the best results/accomplishments are set up as examples." A sample item for mastery climate is "In my work group, each individual's learning and development is emphasized." In the original study, Cronbach's alpha coefficient for performance climate was .79 and that for mastery climate was .84 .

Idea implementation. We assessed idea implementation using Baer's (2012) three-item scale. A sample item is "Employees' ideas have been transformed into usable products, processes, or procedures." Baer reported a Cronbach's alpha coefficient of .95.

Control variables. We controlled for gender, age, average team tenure, gender, and average level of education to account for their potential influence on innovation (Baer, 2012).

\section{Results}

\section{Reliability and Validity of Measures}

We performed Harman's one-factor test to verify the risk of common method bias (Podsakoff et al., 2003), and the results indicated that the majority of the variance was not explained by a single factor $(\operatorname{maximum}=19.1 \%$ ).

It is a requirement for structural equation modeling that the data are normally distributed; thus, we used SPSS 19.0 to calculate the skewness and kurtosis of items. The skewness values ranged between .049 and .852 , and the peak kurtosis value was between 0.083 and 1.205 . These were below the assessment standards, so neither skewness nor kurtosis significantly affected the validity of the analysis. The reliability of all variables was significant (Cohen's kappa $=.72, p<.01)$. 
To further establish the validity of the measures of territoriality, social alienation, performance climate, mastery climate, and idea implementation, we conducted a confirmatory factor analysis and measured the following fit indices: root mean square error of approximation (RMSEA), Tucker-Lewis index (TLI), and confirmatory fit index (CFI). A chi-square $\left(\chi^{2}\right)$ difference test showed that the five-factor model exhibited a better fit than did the four-factor model: $\chi^{2} / d f=2.79$, RMSEA $=.071$, TLI $=.94$, CFI $=$ .97 .

As shown in Table 1, the correlations of the study variables were in the expected directions, and all variables had an acceptable degree of internal consistency.

Insert Table 1 about here.

This study involved individual- and team-level data, so we used two-level hierarchical linear modeling (Mplus 7.4) and estimated the indirect effects of variables and path coefficient values (Preacher, Zyphur, \& Zhang, 2010). In addition, because the indirect effect of multilevel path estimation does not conform to a normal distribution, the parametric bootstrapping method was adopted for repeated sampling (1,000 times). To test the significance of the variables' indirect effects and the moderators' indirect effects, the confidence interval of the indirect effect was used in place of the indirect effects in the hierarchical linear model.

\section{Insert Figure 1 about here.}

\section{Testing of Hypotheses}

The test of the multilevel moderation model (see Figure 1) showed that social alienation mediated the relationship between territoriality and idea implementation. Specifically, territoriality was positively related to social alienation, social alienation was negatively related to idea implementation, and the indirect effect of territoriality on idea implementation through social alienation was $.048(p<.05)$. Thus, Hypothesis 1 was supported.

Mastery climate significantly influenced the random slopes of territoriality and social alienation; thus, Hypothesis 2a was supported. Further, performance climate significantly influenced 
the random slopes of territoriality and social alienation; thus, Hypothesis $2 \mathrm{~b}$ was supported.

\section{Insert Figures $2 \mathrm{a}$ and $2 \mathrm{~b}$ about here.}

We plotted the interaction effects, as shown in Figures $2 \mathrm{a}$ and $2 \mathrm{~b}$. Figure $2 \mathrm{a}$ shows that the relationship between individual territoriality and social alienation was weaker for higher versus lower levels of mastery climate. Figure $2 b$ shows that the relationship between individual territoriality and social alienation was stronger for higher versus lower levels of performance climate.

We used Cohen, Cohen, West, and Aiken's (2003) method to test the moderated mediation model and found that when there was a high level of mastery climate, the indirect effect of territoriality on idea implementation through social alienation was not significant $(r$ $=-.036, n s)$. In contrast, when there was a low level of mastery climate, the indirect effect was significant $(r=.124, p<.05)$. The two indirect effects showed significant differences $(\Delta r=-.16, p<$ $.01 ; 99 \%$ confidence interval [-.413, -.087]). Thus, Hypothesis 3a was supported (see Figure 3a).

However, when there was a high level of performance climate, the indirect effect of territoriality on idea implementation through social alienation was significant $(r=.189, p<.05)$. In contrast, when there was a low level of performance climate, the indirect effect was not significant $(r=.014, n s)$. The two indirect effects showed significant differences $(\Delta r=.175, p<.01 ; 99 \%$ confidence interval [.091, .343]). Thus, Hypothesis 3b was supported (see Figure 3b).

Insert Figures $3 \mathrm{a}$ and $3 \mathrm{~b}$ about here.

\section{Discussion}

From the perspectives of organizational territoriality and motivational climate, we constructed a multilevel model to test the relationship between territoriality and idea implementation. In this model, we examined idea implementation from the perspective of territoriality and analyzed the cross-level moderating roles of different types of motivation climate. 
In conducting this study, we have made several theoretical contributions. First, we initially explored the internal mechanism of territoriality on idea implementation, explaining why good ideas are difficult to implement and also providing new theoretical evidence for the relationship between territoriality and idea implementation. Drawing on social exchange theory (Blau, 1986) and the norm of reciprocity (Gouldner, 1960), we proposed that social alienation would mediate the relationship between territoriality and idea implementation. Initially, when employees' territorial behaviors (construction and maintenance of personal behaviors to control creative ideas) are perceived by other colleagues, territorial employees pay more attention to resources than cooperation (Brown et al., 2005). According to the norm of reciprocity, colleagues respond to this by adopting negative behaviors, namely alienation of territorial employees (e.g., reducing interchangeable resources and communication channels), which, in turn, reduces idea implementation. In general, our results show the potential threat of territoriality and clarify that its impact on idea implementation is exerted through social alienation.

Second, we developed a moderated mediation model to examine the cross-level moderating role of motivational climate on the relationship between individual-level territoriality and social alienation. More specifically, we found that the mediating role of social alienation in the relationship between territoriality and idea implementation is strengthened when there is a higher level of performance climate and weakened when there is a higher level of mastery climate. In our investigation of the effect of individual territoriality on idea implementation, we focused on the way in which the team-level organizational climate influences individuallevel idea implementation. We found that mastery climate can create a context based on shared fate and mutually supportive social exchange, which promotes employees' motivation for idea generation and implementation. Moreover, we found that a mastery climate can inhibit the development of social alienation. Thus, the introduction of the moderating role of mastery climate allowed us to not only identify the positive role of a shared work climate on individual idea implementation, but also show how to reduce the negative effect of territoriality. In contrast, we found that a high performance climate meant that only those individuals who are the 
best achievers are acknowledged as successful (Ames, 1984). Accordingly, individuals in such conditions of forced social comparison maintain their competitive advantage (such as engaging in alienation behaviors) and provide negative feedback to other colleagues' territoriality. Thus, the introduction of the moderating role of performance climate not only confirmed Poortvliet and Giebels's (2012) viewpoint that social comparison and competitive situations may inhibit innovation, but also indicated why excessive competition leads to lower performance.

Our study findings also have some practical implications. First, we found that territoriality inhibits idea implementation. Although territoriality can be a way for employees to maintain their competitiveness, it may be coupled with some disadvantages, including other colleagues' social alienation behavior, which inhibits' employees' idea implementation. Consequently, when managers encourage employees to innovate, they should pay attention to employees' territoriality. Particularly in a highly cooperative task context, managers should aim to choose employees with low territoriality and also improve employees' sense of belonging to attenuate the negative effect of territoriality on team outcomes.

Second, mastery climate and performance climate were found to have a significant influence on idea implementation. On the one hand, organizations should provide a mastery climate characterized by interpersonal trust, sharing, and cooperation to weaken the negative effect of territoriality on idea implementation. On the other hand, organizations should not adopt performance-oriented incentives, such as a performance climate characterized by social comparison and competition, because a high performance climate will lead to negative feedback resulting from territoriality, such as reduced reciprocity, which inhibits idea implementation.

There are some potential limitations to our study that should be acknowledged. First, we examined the effect of territoriality on idea implementation from the perspective of territoriality. Although our results suggest that social alienation fully accounted for the relationship between territoriality and idea implementation, it is possible that there are other mechanisms that could also play a role in explaining this relationship, such as personal conflict, task 
conflict, or affective conflict. Future researchers should explore other mechanisms in the relationship between territoriality and idea implementation. Second, other variables undoubtedly exist that enhance or mitigate the relationship between territoriality and idea implementation. For example, Brown and Robinson (2007) proposed that organizational constructs, such as team psychological ownership and organizational fairness, may be important contextual variables. Thus, future researchers should explore the relationship between territoriality and idea implementation under the context of different organizational climates and cultures. Third, to reduce the potential for common method bias, we adopted a multipoint sampling method and matched the responses of employers and employees. However, the collection of any data from questionnaires leaves room for improvement. A research design in which questionnaires are integrated with experimental study methods could be considered in future research.

\section{References}

Ames, C. (1984). Competitive, cooperative, and individualistic goal structures: A cognitivemotivational analysis. In C. Ames \& R. E. Ames (Eds.), Research on motivation in education (pp. 177-207). Gainesville, FL: Florida Academic Press.

Ames, C. (1992). Achievement goals, motivational climate, and motivational processes. In G. Roberts (Ed.), Motivation in sport and exercise (pp. 161-176). Champaign, IL: Human Kinetics.

Anderson, N., Potočnik, K., \& Zhou, J. (2014). Innovation and creativity in organizations: A state-of-the-science review, prospective commentary, and guiding framework. Journal of Management, 40, 1297-1333. https://doi.org/32w

Avey, J. B., Avolio, B. J., Crossley, C. D., \& Luthans, F. (2009). Psychological ownership: Theoretical extensions, measurement and relation to work outcomes. Journal of Organizational Behavior, 30, 173-191. https://doi.org/dsnxdc

Baer, M. (2012). Putting creativity to work: The implementation of creative ideas in organizations. Academy of Management Journal, 55, 1102-1119. https://doi.org/tvf

Banai, M., \& Reisel, W. D. (2007). The influence of supportive leadership and job characteristics on work alienation: A six-country investigation. Journal of World Business, 42, 463-476. https://doi.org/cz67wm

Blau, P. M. (1986). Exchange and power in social life. New Brunswick, NJ: Transaction Books.

Brislin, R. W. (1980). Translation and content analysis of oral and written materials. In H. C. Triandis \& J. W. Berry (Eds.), Handbook of cross-cultural psychology. Vol. 2: Methodology (pp. 389-444). Boston, MA: Allyn Bacon.

Brown, G., Lawrence, T. B., \& Robinson, S. L. (2005). Territoriality in organizations. Academy of Management Review, 30, 577-594. https://doi.org/dpfgvf

Brown, G., \& Robinson, S. L. (2007). The dysfunction of territoriality inorganizations. In J. Langan-Fox, C. L. Cooper, \& R. J. Klimoski (Eds.), Research companion to the dysfunctional workplace: Management challenges and symptoms (pp. 252-267). Northampton, MA: Edward Elgar. 
Chiaburu, D. S., Diaz, I., \& De Vos, A. (2013). Employee alienation: Relationships with careerism and career satisfaction. Journal of Managerial Psychology, 28, 4-20. https://doi.org/gbcrhq

Cohen, J., Cohen, P., West, S. G., \& Aiken, L. S. (2003). Applied multiple regression correlation analysis for the behavioral sciences (3rd ed.). Mahwah, NJ: Erlbaum.

Edwards, J. R., \& Lambert, L. S. (2007). Methods for integrating moderation and mediation: A general analytic framework using moderated path analysis. Psychological Methods, 12, 1-22. https://doi.org/bxvf4h

Gouldner, A. W. (1960). The norm of reciprocity: A preliminary statement. American Sociological Review, 25, 161-178. https://doi.org/cg3f25

Hobfoll, S. E., Freedy, J., Lane, C., \& Geller, P. (1990). Conservation of social resources: Social support resource theory. Journal of Social and Personal Relationships, 7, 465478. https://doi.org/d3z9cc

Kambil, A. (2002). Good ideas are not enough: Adding execution muscle to innovation engines [White paper]. Chicago, IL: Accenture.

Nerstad, C. G. L., Roberts, G. C., \& Richardsen, A. M. (2013). Achieving success at work: Development and validation of the Motivational Climate at Work Questionnaire (MCWQ). Journal of Applied Social Psychology, 43, 2231-2250. https://doi.org/cbmg

Ntoumanis, N., \& Biddle, S. J. H. (1999). A review of motivational climate in physical activity. Journal of Sports Sciences, 17, 643-665. https://doi.org/b8d9ng

Oldham, G. R., \& Da Silva, N. (2015). The impact of digital technology on the generation and implementation of creative ideas in the workplace. Computers in Human Behavior, 42, 5-11. https://doi.org/f6zkgt

Peng, H. (2013). Why and when do people hide knowledge? Journal of Knowledge Management, 17, 398-415. https://doi.org/f43mvh

Podsakoff, P. M., MacKenzie, S. B., Lee, J.-Y., \& Podsakoff, N. P. (2003). Common method biases in behavioral research: A critical review of the literature and recommended remedies. Journal of Applied Psychology, 88, 879-903. https://doi.org/czw

Poortvliet, P. M., \& Giebels, E. (2012). Self-improvement and cooperation: How exchange relationships promote mastery-approach driven individuals' job outcomes. European Journal of Work and Organizational Psychology, 21, 392-425. https://doi.org/bgvxhv

Preacher, K. J., Zyphur, M. J., \& Zhang, Z. (2010). A general multilevel SEM framework for assessing multilevel mediation. Psychological Methods, 15, 209-233. https://doi.org/dqcxz7

Richter, A. W., Hirst, G., van Knippenberg, D., \& Baer, M. (2012). Creative self-efficacy and individual creativity in team contexts: Cross-level interactions with team informational resources. Journal of Applied Psychology, 97, 1282-1290. https://doi.org/f4fcsz

Roberts, G. C. (2012). Motivation in sport and exercise from an achievement goal theory perspective: After 30 years, where are we? In G. C. Roberts \& D. Treasure (Eds.), Advances in motivation in sport and exercise (Vol. 3, pp. 5-58). Champaign, IL: Human Kinetics.

Salancik, G. R., \& Pfeffer, J. (1978). A social information processing approach to job attitudes and task design. Administrative Science Quarterly, 23, 224-253. https://doi.org/bghk77

Schulte, M., Ostroff, C., Shmulyian, S., \& Kinicki, A. (2009). Organizational climate configurations: Relationships to collective attitudes, customer satisfaction and financial performance. Journal of Applied Psychology, 94, 618-634. https://doi.org/fjmcsv

Škerlavaj, M., Černe, M., \& Dysvik, A. (2014). I get by with a little help from my supervisor: Creative-idea generation, idea implementation, and perceived supervisor support. The Leadership Quarterly, 25, 987-1000. https://doi.org/cbmh

Swift, M., Balkin, D. B., \& Matusik, S. F. (2010). Goal orientations and the motivation to share knowledge. Journal of Knowledge Management, 14, 378-393. https://doi.org/cnxgh7 
Zhang, G., Chan, A., Zhong, J., \& Yu, X. (2016). Creativity and social alienation: The costs of being creative. The International Journal of Human Resource Management, 27, 12521276. https://doi.org/cbmj 
Table 1. Means, Standard Deviations, and Correlations for Study Variables

\begin{tabular}{|c|c|c|c|c|c|c|c|c|c|c|c|}
\hline & $M$ & $S D$ & 1 & 2 & 3 & 4 & 5 & 6 & 7 & 8 & 9 \\
\hline 1. Gender & 0.65 & 0.49 & - & & & & & & & & \\
\hline 2. Age (years) & 28.15 & 6.12 & -.04 & - & & & & & & & \\
\hline 3. Job tenure (years) & 4.36 & 3.23 & .01 & $.17 *$ & - & & & & & & \\
\hline 4. Level of education & 5.94 & 0.78 & .02 & .09 & -.04 & - & & & & & \\
\hline 5. Territoriality & 4.39 & 1.01 & .05 & -.11 & $.18^{*}$ & .05 & $(.85)$ & & & & \\
\hline 6. Social alienation & 4.72 & 0.97 & -.06 & .08 & -.09 & .12 & $.51^{* *}$ & (.79) & & & \\
\hline 7. Mastery climate & 4.58 & 0.86 & .04 & .02 & -.03 & .07 & -.03 & -.043 & $(.84)$ & & \\
\hline 8. Performance climate & 3.87 & 0.95 & .03 & -.01 & .05 & -.06 & .08 & .095 & -.07 & $(.79)$ & \\
\hline 9. Idea implementation & 4.91 & 1.84 & -.07 & .06 & .04 & .08 & $-.28 * *$ & $-.29 *$ & .09 & .12 & $(.95)$ \\
\hline
\end{tabular}

Note. Gender was dummy-coded as $0=$ female, $1=$ male. Level of education was dummy-coded as $1=$ primary school, $2=$ high school, $3=3$-year technical college, 4 = bachelor's degree, $5=$ master's degree, $6=$ doctoral degree. Cronbach's alphas are shown in parentheses on the diagonal. ${ }^{*} p<.05,{ }^{* *} p$ $<.01$. 


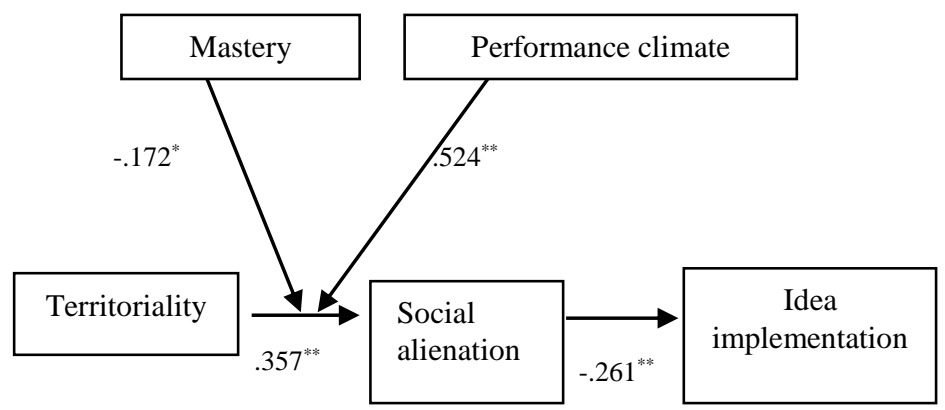

Team-level variables

Individual-le variables

Figure 1. Path coefficient results.

Note. ${ }^{*} p<.05,{ }^{* *} p<.01$.

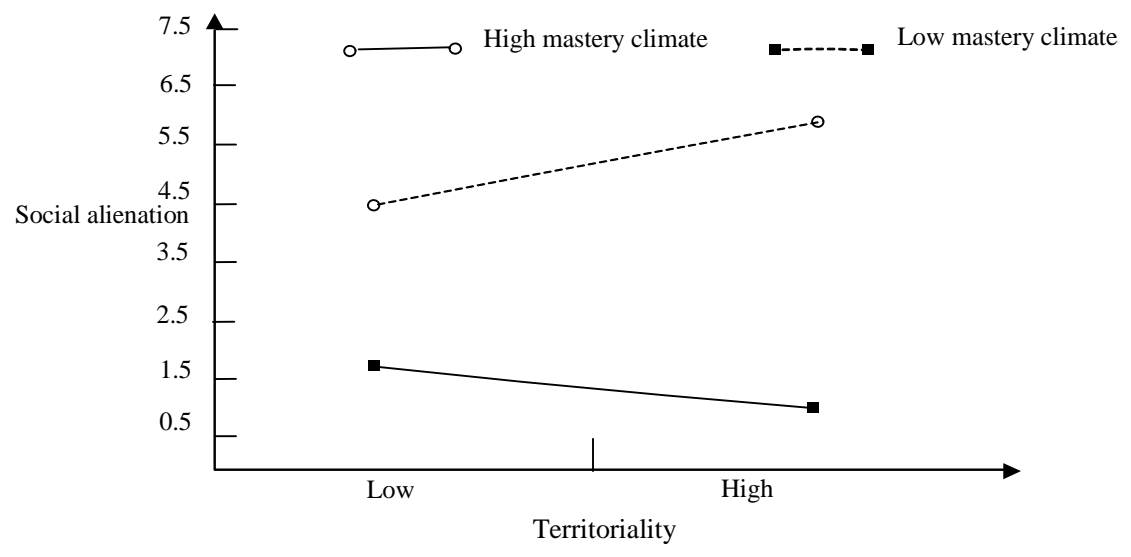

Figure 2a. Interactive effects of territoriality and mastery climate on social alienation. 


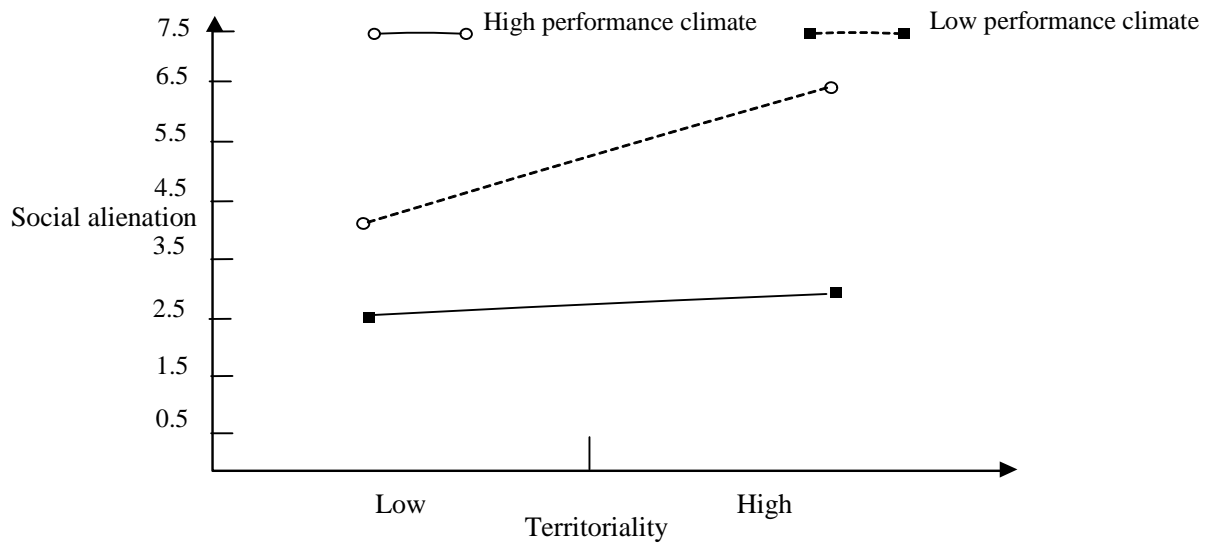

Figure 2b. Interactive effects of territoriality and performance climate on social alienation.

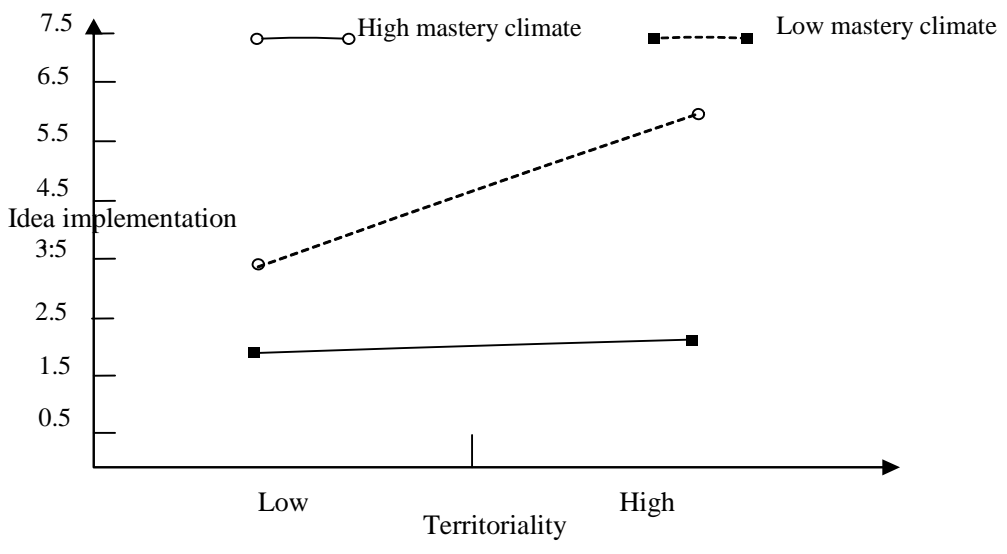

Figure 3a. Interactive effects of territoriality and mastery climate on idea implementation. 


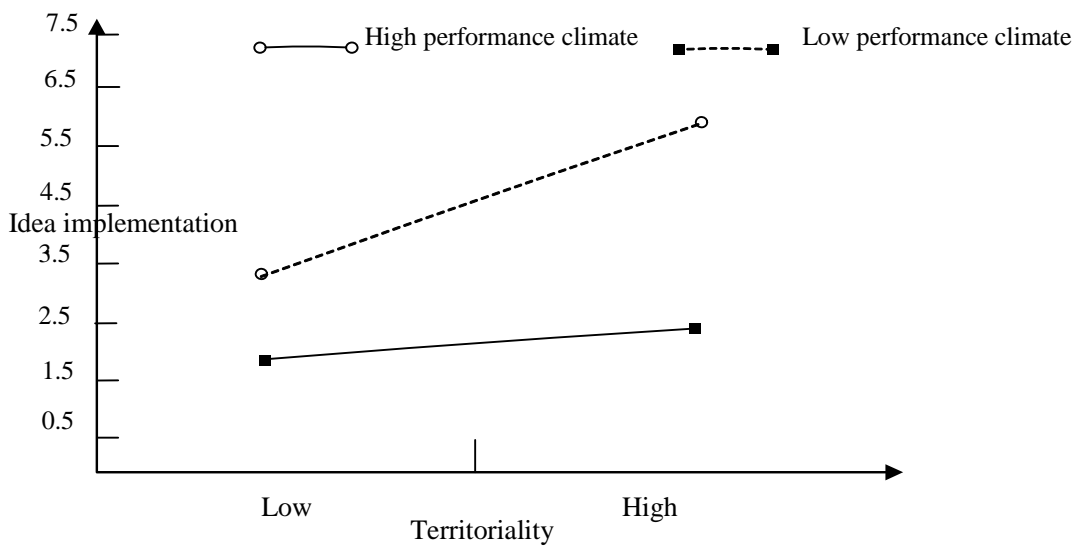

Figure 3b. Interactive effects of territoriality and performance climate on idea implementation. 